\title{
MAGNETIC RESONANCE IMAGING EVALUATION OF LIGAMENTOUS TEARS OF THE KNEE JOINT AND ASSOCIATION OF MENISCAL TEARS WITH ANTERIOR CRUCIATE LIGAMENT TEARS
}

\author{
Bommandapalli Madhaiah Seshadri1, Suresh Ashwathappa², Indira Narayana Swamy³ \\ ${ }_{1}^{1}$ Assistant Professor, Department of Radiodiagnosis, Vydehi Institute of Medical Sciences \& Research Centre, Bangalore. \\ ${ }^{2}$ Associate Professor, Department of Radiodiagnosis, Vydehi Institute of Medical Sciences \& Research Centre, Bangalore. \\ ${ }^{3}$ Professor, Department of Radiodiagnosis, Vydehi Institute of Medical Sciences \& Research Centre, Bangalore.
}

\begin{abstract}
Anterior cruciate ligament tears are most commonly sustained sports injury, often occurring in association with meniscal tears and trauma to other ligamentous structures around the knee. Magnetic resonance imaging is vital in assessing acute knee injuries and plays an important role in deciding treatment options and planning surgical intervention. Magnetic Resonance (MR) imaging has emerged as investigation of choice to evaluate the status of the ACL and other associated structures in the knee.
\end{abstract}

\section{AIMS AND OBJECTIVES}

The purpose of this study is to determine the association of subtle meniscal injury in the presence of anterior cruciate ligament injury and other associated pathology on MR imaging.

\section{MATERIAL AND METHODS}

A prospective cross-sectional case study done on 40 patients including both the sexes in age group of 15 to 35 years presenting with knee joint injuries and subsequently underwent MRI of the knee joint. The data was analysed and the findings on MRI were correlated with that of arthroscopy and/or operative findings.

\section{RESULTS}

The commonest soft tissue injury identified on MRI of the knee joint was ACL injury and it was associated with injuries of medial meniscus followed by of lateral meniscus, medial collateral ligament and lateral collateral ligament.

\section{CONCLUSION}

MRI is an excellent, non-invasive, radiation free imaging modality with multiplanar capabilities and excellent soft tissue delineation. It can accurately detect, localize and characterize various internal derangements of the knee joint and help in arriving at a correct anatomical diagnosis, thereby guiding further management of the patient. Medial meniscal tears were more commonly associated with ACL tear. Various patterns of meniscal injuries were identified in this study, out of which bucket handle pattern was more common among medial meniscal tears and radial pattern was common in the lateral meniscal injuries. Radiologists while interpreting MR studies of knee injuries, should be aware of these associations.

\section{KEYWORDS}

Magnetic Resonance Imaging, Anterior Cruciate Ligament, Posterior Cruciate Ligament, Medial Meniscus, Lateral Meniscus, Medial Collateral Ligament, Lateral Collateral Ligament.

HOW TO CITE THIS ARTICLE: Seshadri BM, Ashwathappa S, Swamy IN. Magnetic resonance imaging evaluation of ligamentous tears of the knee joint and association of meniscal tears with anterior cruciate ligament tears. J. Evolution Med. Dent. Sci. 2016; 5(43): 2664-2668, DOI: $10.14260 /$ jemds/2016/624

\section{INTRODUCTION}

Knee joint is a common site of injury. Most cases are due to trauma, repetitious activities and due to sports. Rotational, compressive and transaxial forces may act together or separately to produce knee injuries. Multiple imaging modalities are currently used to evaluate pathologic conditions of the knee including conventional radiography, fluoroscopy, ultrasonography, nuclear medicine and MR imaging.

In cases of fractures, the radiographic diagnosis is frequently obvious. However, some fractures and most soft tissue injuries around the knee have subtle radiographic

Financial or Other, Competing Interest: None.

Submission 25-01-2016, Peer Review 05-05-2016,

Acceptance 11-05-2016, Published 28-05-2016.

Corresponding Author:

Dr. Indira Narayana Swamy,

\#2066, 16 ${ }^{\text {th }}$ 'D' Main, HAL-II Stage,

Bangalore-560008.

E-mail: drindiraniranjan@gmail.com

DOI: $10.14260 /$ jemds/2016/624 findings and may be difficult to detect even with optimal radiographic views. The use of fluoroscopy and sonography to guide interventional procedures and Computerized Tomography (CT) to evaluate complex fractures has become routine. ${ }^{1}$

Magnetic resonance imaging has revolutionized our ability to understand the soft tissue anatomy and pathology of musculoskeletal system. Increased soft tissue contrast coupled with multiplanar capability has made Magnetic Resonance Imaging an ideal modality for imaging complex anatomy.2,3

Another advanced modality in the management of ligamentous pathologies of knee joint is arthroscopy, which can be used in dual mode, either as diagnostic or as a therapeutic tool. 4

ACL tears are commonly sustained sports injury. Although ACL injuries may occur in isolation, they are most commonly associated with other knee injuries. These associated injuries are readily detected on MR imaging and include posterior cruciate ligament tears, meniscal injuries, collateral ligament injuries and osseous lesions. ${ }^{5}$ 


\section{The Objectives of the Present Study are}

1. To determine the efficacy of MRI in the diagnosis of anterior cruciate ligament and other ligamental tears, bone and bone marrow injuries by correlating with arthroscopy and/or operative findings.

2. To determine the association of anterior cruciate ligament tears with posterior cruciate ligament tears, meniscal injuries, collateral ligamental injuries and osseous lesions.

\section{METHODS AND METHODOLOGY}

A prospective, cross-sectional case study was performed on 40 patients in the age group of 15-35, visiting Department of Orthopaedics with history of knee injuries were subjected to MRI. Study duration was twelve months from January 2012 to December 2012. Findings of MRI were compared with arthroscopy and/or open surgery. Patients who were previously operated for knee injuries and patients with absolute contraindications for MRI were excluded.

MRI knee was done using 1.5 Tesla Philips Achieva Machine. Different sequences were performed like PDW-sag, PDW-SPIR-sag, STIR-coronal, T2-coronal, T1-coronal, T1axial, STIR-axial and STIR-axial with thin cuts and 3D WATSsag. Data was entered into a computerized Excel (Microsoft Excel 2007) spread sheet and analysed using Epi Info version 3.4.1. Descriptive analysis was done (Means, proportions and percentages) for demographic details. The categorical variables were compared using Chi square test and Fisher's exact test. $P$ value of $<0.05$ was considered significant.

\section{RESULTS}

Out of 40 patients, 35 (87.5\%) were males and 5 (12.5\%) were females (Chart 1). Age related distribution was maximum between age group of 26-30 years (14 cases 35\%) suggesting physically active time (Figure 2 ).

MRI findings are well correlated with arthroscopic/surgical findings. Correlation between MRI and arthroscopic/surgical findings were statistically significant (Table 1).

Out of 40 patients, $38(95 \%)$ had abnormal ACL and $2(5 \%)$ had normal ACL; 12 (30\%) had abnormal contour without discontinuity of the ligament fibres; 22 (55\%) had discontinuity of ACL fibres; 4 (10\%) had discontinuity of ACL fibres with buckling of PCL (Table 3).

One patient revealed PCL tear; however, 4 patients had PCL buckling on MRI (12.5\%). The rest 35 (87.5\%) had normal PCL (Table 4).

Of 40 patients, 22 (55\%) revealed injury to medial meniscus (MM); 12 (30\%) had evidence of grade II injury to the posterior horn of medial meniscus; 6 (15\%) patients revealed grade II signal intensity changes in anterior horn on MRI; 4 (10\%) patients showed grade III tear of the anterior horn as well as posterior horn of medial meniscus (Table 5).

In comparison to medial meniscus, injury to lateral meniscus was less common in our study; 14 (35\%) patients showed evidence of injury to the lateral meniscus (LM); 7 $(17.5 \%)$ cases were identified having grade III tear of posterior horn of lateral meniscus (LM); 4 (10\%) patients revealed grade II signal intensity change of anterior horn; 3 (7.5\%) patients revealed tear in both the anterior and posterior horns of grade III (Table 6).
Out of 40 cases in our study, 2 (5.0\%) cases revealed injury to the MCL. The rest 38 cases revealed normal MCL. In our study out of 40 cases, 1 patient had Lateral Collateral Ligament (LCL) injury. The rest 39 revealed normal LCL.

$23(57.5 \%)$ patients had knee joint effusion; 12 (30\%) patients were detected having minimal joint effusion; 8 (20\%) patients revealed moderate joint effusion; 3 (7.5\%) patients presented with massive joint effusion on MRI.

$5(12.5 \%)$ patients revealed changes in the femur; $4(10 \%)$ patients revealed marrow oedema in medial femoral condyle on MRI; $1(2.5 \%)$ case revealed fracture in the lateral femoral condyle. The rest 35 patients revealed normal bony contour. Among the 40 patients, $5(12.5 \%)$ had changes in tibia; $2(5 \%)$ had bone marrow oedema/contusion, identified; 3 (7.5\%) showed fracture of lateral tibial condyle.

\section{Associations}

Bucket handle tear of medial meniscus was the most common pattern followed by horizontal tears. Radial tear was the most common pattern found in lateral meniscus followed by complex tears.

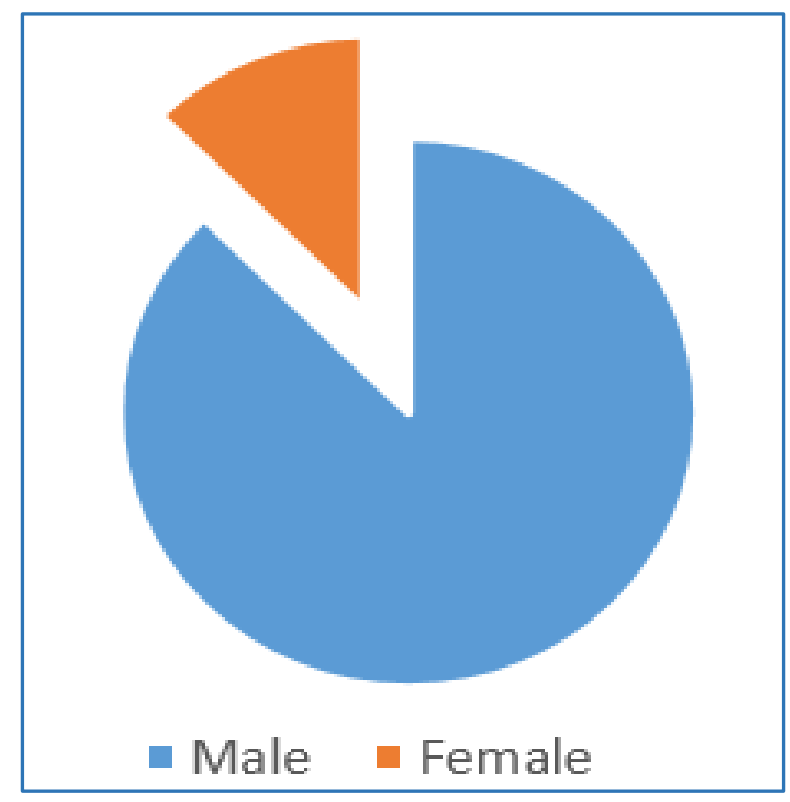

Fig. 1: Showing Gender Distribution

Out of 40 patients, 35 were males $(87.5 \%)$ and 5 were females $(12.5 \%)$.

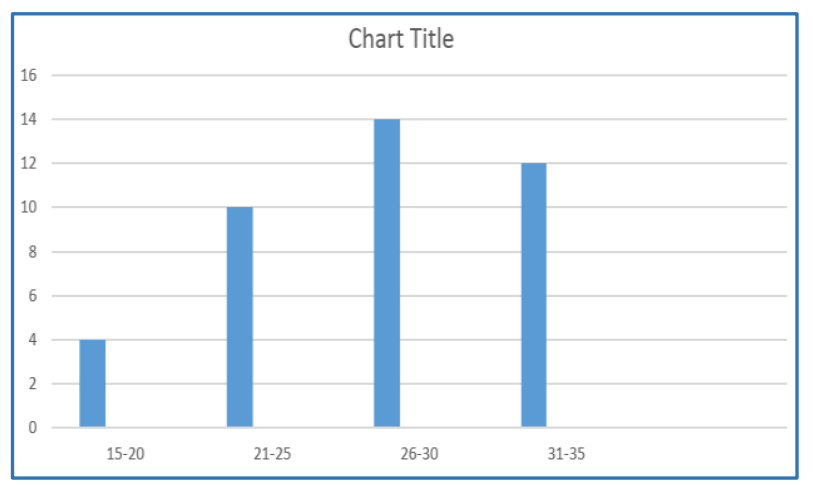

Fig. 2: Age Distribution of Patients Studied

Age related distribution was maximum between age group of $26-30$ years ( 14 cases, $35 \%$ ). 


\begin{tabular}{|c|c|c|}
\hline Correlation & $\begin{array}{c}\text { Number } \\
(\mathbf{n = 4 0 )}\end{array}$ & $\mathbf{\%}$ \\
\hline No & 2 & $5 \%$ \\
\hline Yes & 38 & $95 \%$ \\
\hline P value: 0.01 Statistically significant & & \\
\hline \multicolumn{2}{|c|}{ Table 1: Correlation of MRI Diagnosis with } \\
Arthroscopic/Surgical Findings \\
\hline
\end{tabular}

\begin{tabular}{|c|c|c|}
\hline MRI Findings & Positive Findings (n=40) & $\mathbf{\%}$ \\
\hline ACL tear & 38 & $95 \%$ \\
\hline PCL tear & 5 & $12.5 \%$ \\
\hline MM tear & 22 & $55 \%$ \\
\hline LM tear & 14 & $35 \%$ \\
\hline MCL tear & 2 & $5 \%$ \\
\hline LCL tear & 1 & $2.5 \%$ \\
\hline Joint effusion & 23 & $57.5 \%$ \\
\hline Femur lesion & 5 & $12.5 \%$ \\
\hline Tibia lesion & 5 & $12.5 \%$ \\
\hline \multicolumn{2}{|c|}{ Table 2: Spectrum of MRI Findings Seen } \\
\hline \multicolumn{2}{|c|}{}
\end{tabular}

\begin{tabular}{|c|c|c|}
\hline ACL Tear & $\begin{array}{c}\text { Number } \\
(\mathbf{n = 4 0 )}\end{array}$ & $\mathbf{\%}$ \\
\hline No & 2 & $05 \%$ \\
\hline Yes & 38 & $95 \%$ \\
\hline Partial & 12 & \\
\hline Complete & 26 & \\
\hline P value: 0.032 Statistically significant & \\
\hline \multicolumn{2}{|c|}{ Table 3: ACL Tear on MRI } \\
\hline
\end{tabular}

\begin{tabular}{|c|c|c|}
\hline PCL Tear & $\begin{array}{c}\text { Number } \\
(\mathbf{n = 4 0 )}\end{array}$ & \% \\
\hline No & 35 & $87.5 \%$ \\
\hline Yes & 5 & $12.5 \%$ \\
\hline $\begin{array}{c}\text { P value: 0.012 Statistically } \\
\text { significant }\end{array}$ & \\
\hline \multicolumn{2}{|c|}{ Table 4: PCL Tear on MRI } \\
\hline
\end{tabular}

\begin{tabular}{|c|c|c|}
\hline MM Tear & $\begin{array}{c}\text { Number } \\
(\mathbf{n = 4 0 )}\end{array}$ & $\mathbf{\%}$ \\
\hline No & 18 & $45 \%$ \\
\hline Yes & 22 & $55 \%$ \\
\hline Grade I & -- & -- \\
\hline Grade II & 18 & $45 \%$ \\
Grade III & 4 & $10 \%$ \\
\hline P value: 0.023 Statistically significant & \\
\hline \multicolumn{2}{|c|}{ Table 5: MM Tear on MRI } \\
\hline
\end{tabular}

\begin{tabular}{|c|c|c|}
\hline LM Tear & $\begin{array}{c}\text { Number } \\
(\mathbf{n = 4 0 )}\end{array}$ & $\mathbf{\%}$ \\
\hline No & 26 & $65 \%$ \\
\hline Yes & 14 & $35 \%$ \\
\hline Grade I & -- & -- \\
\hline Grade II & 11 & $27.5 \%$ \\
Grade III & 3 & $7.5 \%$ \\
\hline P value: 0.032 Statistically \\
significant & \\
\hline \multicolumn{2}{|c|}{ Table 6: LM Tear on MRI } \\
\hline
\end{tabular}

Patterns of MM Tear

\begin{tabular}{|c|c|c|c|c|c|}
\hline & Horizontal & $\begin{array}{c}\text { Bucket } \\
\text { Handle }\end{array}$ & Radial & Flap & Complex \\
\hline $\begin{array}{c}\text { ACL } \\
\text { torn }\end{array}$ & 4 & 10 & 3 & 1 & 4 \\
\hline $\begin{array}{c}\text { ACL } \\
\text { intact }\end{array}$ & - & 1 & - & - & - \\
\hline $\begin{array}{r}\text { Table 7: Association between Tear of Anterior Cruciate } \\
\text { Ligament and Configuration of Medial Meniscal Tear }\end{array}$ \\
?
\end{tabular}

Patterns of LM Tear on MRI

\begin{tabular}{|c|c|c|c|c|c|}
\hline & Horizontal & $\begin{array}{c}\text { Bucket } \\
\text { Handle }\end{array}$ & Radial & Flap & Complex \\
\hline $\begin{array}{c}\text { ACL } \\
\text { torn }\end{array}$ & 2 & 2 & 6 & 1 & 3 \\
\hline $\begin{array}{c}\text { ACL } \\
\text { intact }\end{array}$ & - & 1 & - & - & - \\
\hline $\begin{array}{c}\text { Table 8: Association between Tear of Anterior Cruciate } \\
\text { Ligament and Configuration of Lateral Meniscal Tear }\end{array}$ \\
\hline
\end{tabular}

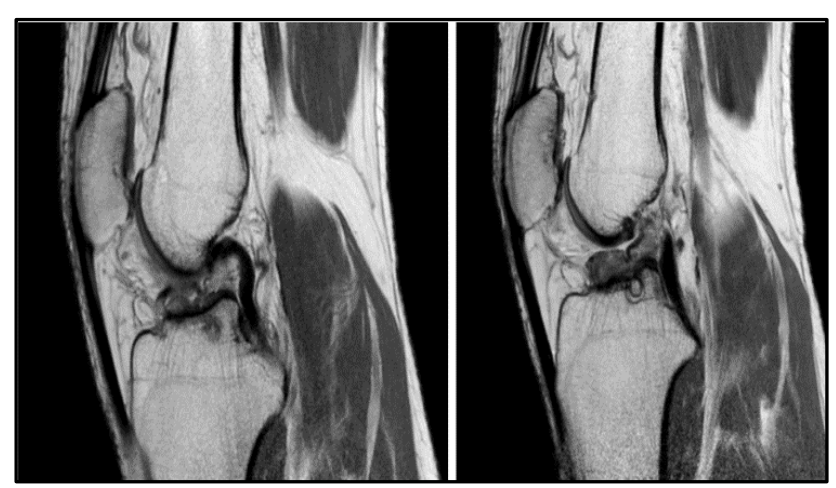

Image 1: MRI showing Complete ACL Tear with PCL Buckling

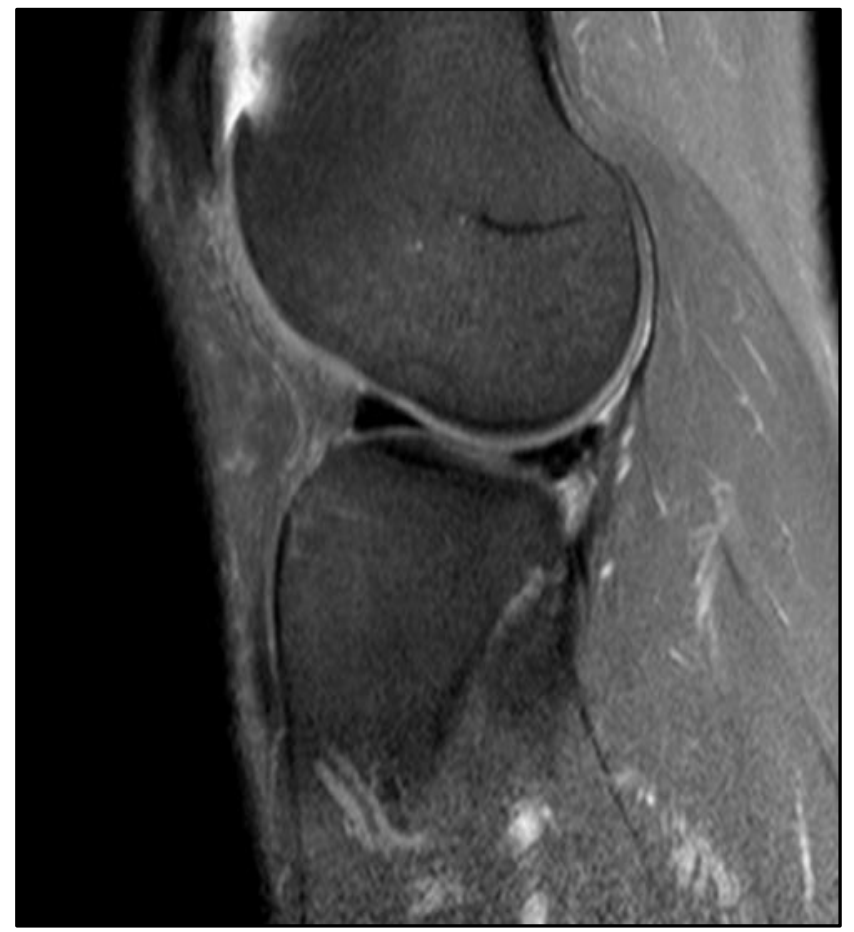

Image 2: MRI showing Grade III Tear of Lateral Meniscus Posterior Horn 


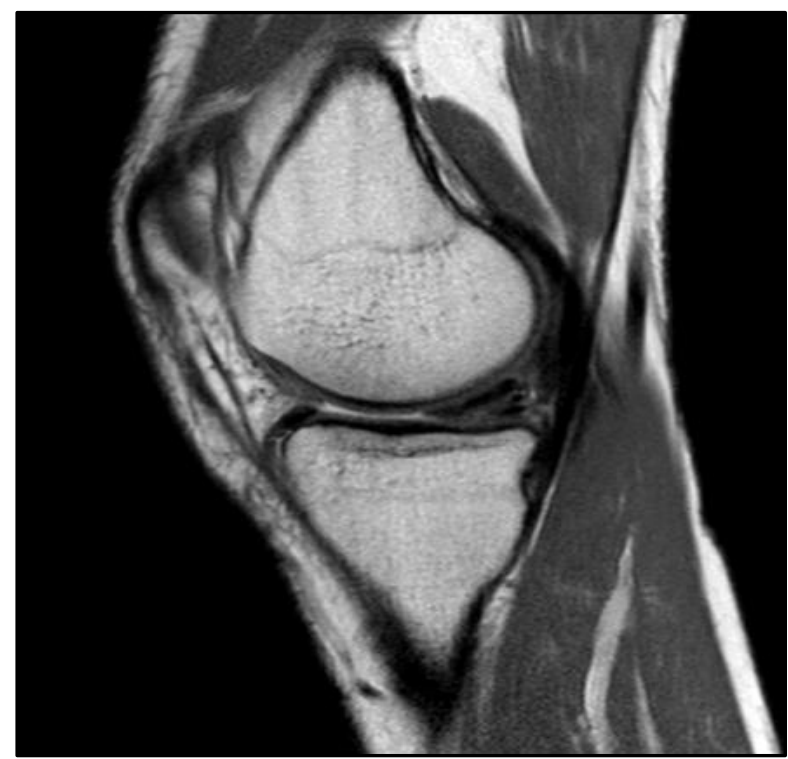

Image 3: MRI showing Grade III Medial Meniscus, Posterior Horn Tear

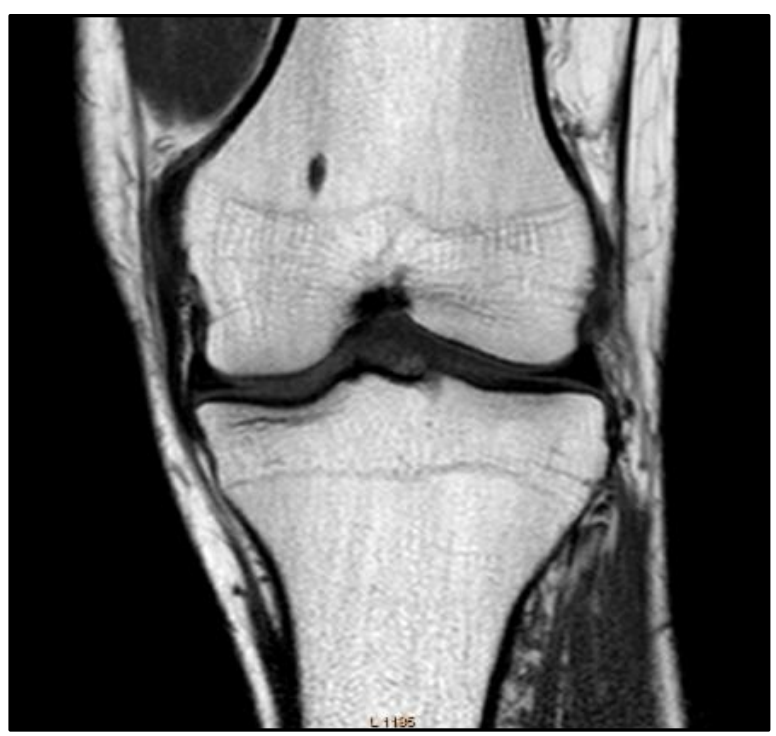

Image 4: MRI showing Medial Collateral Ligament Injury

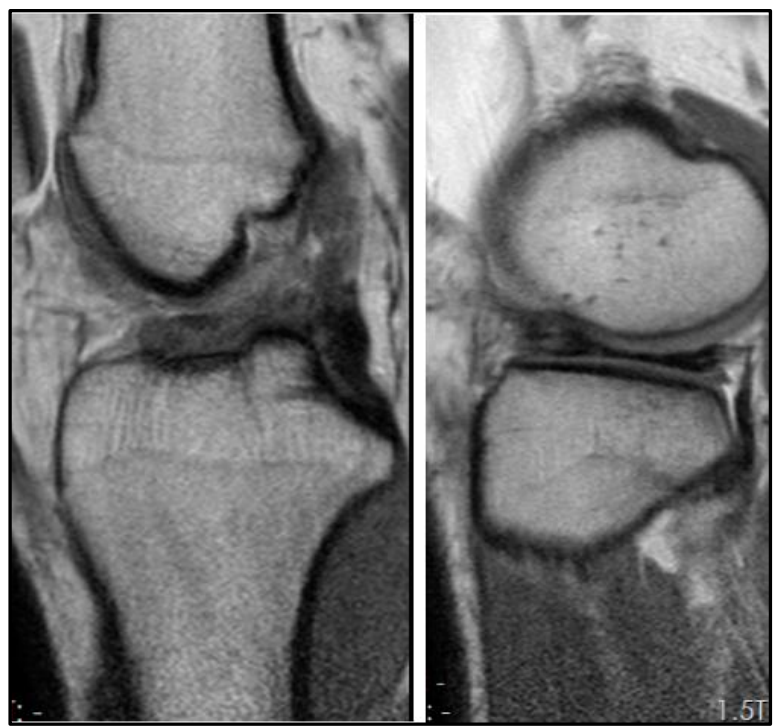

Image 5: MRI showing ACL Tear Associated with Bucket Handle of Lateral Meniscus

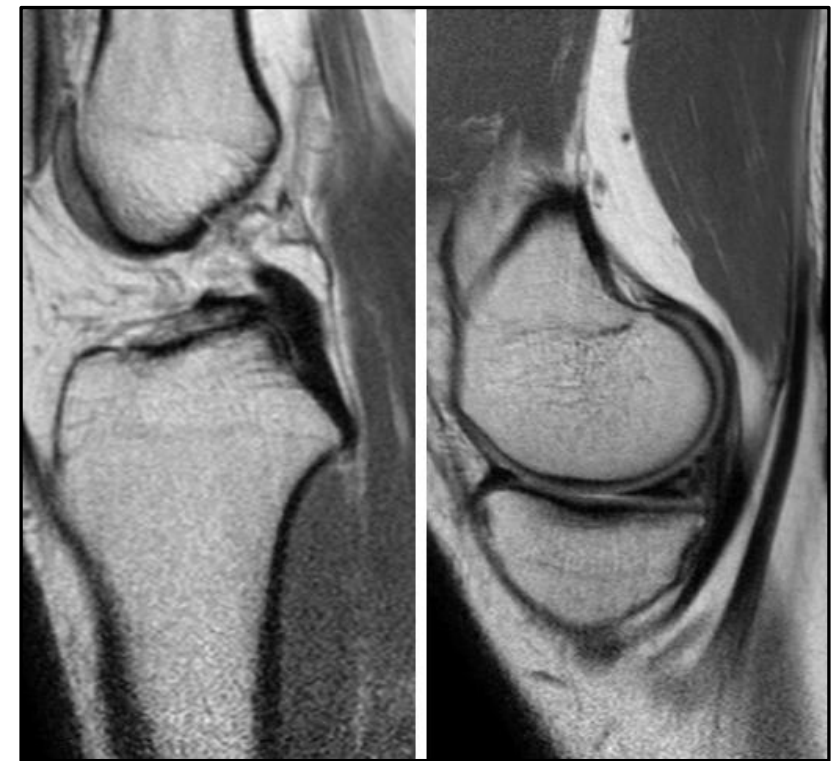

Image 6: MRI showing ACL Tear Associated with Posterior Horn of Medial Meniscus

\section{DISCUSSION}

The role of Magnetic Resonance Imaging has steadily increased and now it has become the first line of investigation for most of the lesions of knee. Complete evaluation of all the internal structures of the knee was not possible with other modalities like Conventional Radiography, Arthrography and Ultrasonography and Computed Tomography. Even with arthroscopy, lesions such as peripheral meniscal tears, inferior surface tears and osteochondritis dissecans without articular cartilage damage are most often not detected. Multiplanar MR images provide significant improvement in assessing these structures.

In our study, a correlation of MRI findings with arthroscopic/surgical findings was performed in all 40 patients, among which in 38 patients (95\%) MRI findings are well correlated with arthroscopic/surgical findings. Correlation between MRI and arthroscopic/surgical findings were statistically significant. ${ }^{6}$

In our study among the ligamentous and meniscal injuries, ACL tear was the most common seen in 38 patients (95\%) followed by the Medial Meniscal injuries seen in 22 patients (55\%) with grade II type injury being commonest. Joint effusions were the commonest finding affecting 23 (57.5\%) patients.

Our study showed ACL tear in 38 patients (95\%), among these 12 (30\%) were partial tears and 26 (65\%) were complete tears. Singh JP et al in their series of 173 patients, 78 patients $(45.08 \%)$ showed ACL tears, among these 52 (66.67\%) were partial, 16 (20.51\%) were complete and 10 (12.82\%) cases showed non-visualization of ACL. The authors concluded that ACL tears are more common than other ligamentous injuries with partial tears being commoner. ${ }^{7}$

Posterior cruciate ligament injuries were found to be relatively uncommon in our study, we found in only 5 patients $(12.5 \%)$ and tears were demonstrated as thickening of the ligament with abnormal signal intensity (partial tear) and 1 patient had complete tear. Sonnin et al found the incidence of PCL tear to be 3 percent; in a series of study analysing 350 cases of knee injury, only 10 patients had PCL tear. ${ }^{8}$ 
In our study, MCL tears (5\%) were found to be more common than the LCL tear (2.5\%). All these cases had history of trauma and were associated with multiple injuries, which was also observed by Mink JH et al. ${ }^{9}$

There was predominance of MM tears over LM tears in our study. MM tears were found in $22(55 \%)$ with grade I tear in none, grade II tear in $18(45 \%)$ and grade III in $4(10 \%)$ and LM tear in $14(35 \%)$ with grade I tear in 0 , grade II tear in 11 $(27.5 \%)$ and grade III in $3(7.5 \%)$. Grade II tears were more common in both the menisci; MM 18 (45\%) and LM 11 (27.5\%). This well correlated with the study done by Singh JP et $\mathrm{al}^{10}$ in a series of 173 cases, of which they found 57 (38.23\%) patients showed MM tear and $28(29.41 \%)$ patients showed LM tear.

Lateral discoid meniscus with appearance of bow tie configuration in more than two contiguous slices on sagittal images was found in one patient.

The cystic lesions encountered were meniscal cyst, parameniscal cyst and popliteal cyst (Baker's cyst). The meniscal cysts and parameniscal cysts were found to be associated with tear of the lateral meniscus in 2 cases and medial meniscus in 1 case. These findings were correlated with findings described by Thomas H. Berquist. ${ }^{11}$

In our study Osseous/Osteochondral lesions were seen in 7 cases (17.5\%). Most of these were bony contusions involving the femoral and tibial condyles. These findings were correlated with findings described by Thomas $\mathrm{H}$. Berquist ${ }^{11}$

The finding of haemarthrosis was associated in two cases with presence of intercondylar fractures. These findings well correlated with findings described by Thomas H. Berquist. ${ }^{11,12}$

\section{Associated Injuries}

In our study, we found 36 cases of combined injuries and 4 cases of isolated injuries. The predominant pattern was ACL tear and MM tears (23) followed by ACL tear and LM tear (12), which well correlated with a study by Ali Akbar Esmail Jah et al,13 in a series of 17 cases of concomitant injuries at MRI and arthroscopy. The predominant pattern was anterior cruciate ligament rupture and medial meniscus tear (16 patients), followed by anterior cruciate ligament and lateral meniscus ( 9 patients), anterior cruciate ligament, medial meniscus and lateral ligament ( 5 patients).

Among the meniscal injuries the various patterns of tears that we came across were horizontal tears, bucket handle tears, radial tears, flap tears and complex tears. In the cases with medial meniscus, tear bucket handle tear (45.4\%) were commonly seen in our study and radial pattern of tear (42.8\%) was common in cases with lateral meniscus.

\section{CONCLUSION}

MRI is an excellent, non-invasive, radiation free imaging modality with multiplanar capabilities and excellent soft tissue delineation. It can accurately detect, localize and characterize various internal derangements of the knee joint and help in arriving at a correct anatomical diagnosis, thereby guiding further management of the patient.
Furthermore, the MRI diagnosis of internal derangements correlated with arthroscopy findings and it was found that the MR findings were in par with that of arthroscopy.

Most common injury was ACL tear, of which complete tears were commonest. ACL injuries were more commonly associated with other injuries that were readily detected on MR imaging. The associated injuries include PCL injuries, MM and LM injuries, MCL, LCL osseous injuries of varying grades and patterns. Radiologists while interpreting MR studies of knee injuries should be aware of these associations.

\section{REFERENCES}

1. Matthew A Frick, Doris E Wenger, Mark Adkins. MR Imaging of synovial disorders of knee: an update. Radiol Clin N Am 2007;45(6):1017-1031.

2. Omar Faiz, David Moffat. The knee joint and popliteal fossa. In: Omar Faiz, David Moffat, editor. Anatomy at a glance. University of Cardiff: Blackwell science Ltd 2002; $5^{\text {th }}$ edn.

3. Martin L Schwartz. Magnetic resonance imaging of knee ligaments and tendons. Operative Techniques in Sports Medicine 1995;3(1):27-34.

4. Terry R Youcham, Norman W Ketter, Michael S Barry, et al. Diagnostic imaging of the musculoskeletal system. Essentials of skeletal radiology. Terry R Youcham and Lindsay J Rowe. Published by: Lippincott Williams \& Wilkins, USA 2005; vol-1(3rd edn):554.

5. Newman-Sanders A, Hine AL. The musculoskeletal system 2: lower limb. In: Paul Butler. Adam WM Mitchell, Harold Ellis editor. Applied radiological anatomy of knee. India Cambridge university press 2005;1 1st edn:363-366.

6. Venkataswamy Reddy M. Statistics for mental health care research. In: Subba Rao, S Jingar editors, INDIA 2002.

7. Mink JH. The cruciate and collateral ligaments, in Mink JH, Reicher MA, Crues JV, (eds): MRI of the Knee. New York, NY, Raven 1993;2nd edn:141-188.

8. Dietz GW, Wilcox DM, Montgomery JB. Segondtibial condyle fracture: lateral capsular ligament avulsion. Radiology 1986;159(2):467-9.

9. Sonin AH, Fitzgerald SW, Friedman H. MR imaging of posterior cruciate ligament; normal, abnormal and associated injury pattern. Radiographics 1995;15(3):551561.

10. Singh JP, Garg L, Shrimali R, et al. MR Imaging of knee with arthroscopic correlation in twisting injuries. Indian journal of radiology and imaging 2004;14(1):33-40.

11. Berquist TH. Osseous and myotendinous injuries about the knee. Radiol Clin North Am 2007;45(6):955-68.

12. Bernard Rosner. Fundamentals of biostatistics. In: Bernard Rosner, editor. Fundamentals of biostatistics. Duxbury: Blackwell 2000; $5^{\text {th }}$ edn:80-240.

13. Jah AAE, Keyhani S, Zarei R, et al. Accuracy of MRI in comparison with clinical and arthroscopic findings in ligamentous and meniscal injuries of the knee. Acta Orthop Belg 2005;71(2):189-96. 